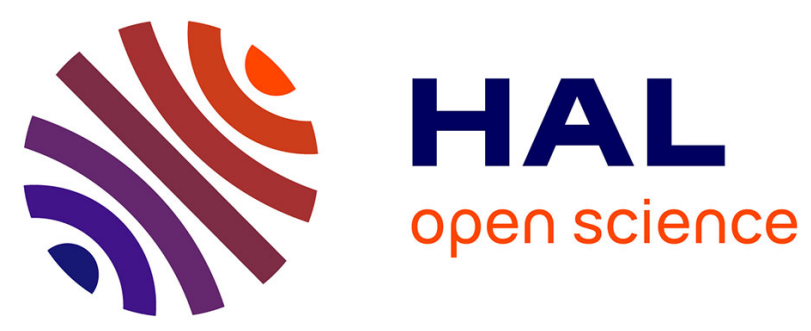

\title{
Understanding Oxygen Release from Nanoporous Perovskite Oxides and Its Effect on the Catalytic Oxidation of $\mathrm{CH} 4$ and $\mathrm{CO}$
}

Elisa Poffe, Helena Kaper, Benedikt Ehrhardt, Lara Gigli, Daniel Aubert, Luca Nodari, Silvia Gross, Simone Mascotto

\section{To cite this version:}

Elisa Poffe, Helena Kaper, Benedikt Ehrhardt, Lara Gigli, Daniel Aubert, et al.. Understanding Oxygen Release from Nanoporous Perovskite Oxides and Its Effect on the Catalytic Oxidation of CH4 and CO. ACS Applied Materials \& Interfaces, 2021, 10.1021/acsami.1c02281 . hal-03419535

\section{HAL Id: hal-03419535 \\ https://hal.science/hal-03419535}

Submitted on 8 Nov 2021

HAL is a multi-disciplinary open access archive for the deposit and dissemination of scientific research documents, whether they are published or not. The documents may come from teaching and research institutions in France or abroad, or from public or private research centers.
L'archive ouverte pluridisciplinaire HAL, est destinée au dépôt et à la diffusion de documents scientifiques de niveau recherche, publiés ou non, émanant des établissements d'enseignement et de recherche français ou étrangers, des laboratoires publics ou privés. 


\title{
Understanding Oxygen Release from Nanoporous Perovskite Oxides and Its Effect on the Catalytic Oxidation of $\mathrm{CH}_{4}$ and $\mathrm{CO}$
}

\author{
Elisa Poffe ${ }^{1,2}$, Helena Kaper ${ }^{3}$, Benedikt Ehrhardt ${ }^{1}$, Lara Gigli ${ }^{4}$, Daniel Aubert ${ }^{3}$, Luca Nodari ${ }^{2,5}$, Silvia Gross ${ }^{2,6}$ and Simone \\ Mascotto $^{1^{*}}$ \\ ${ }^{1}$ Institut für Anorganische und Angewandte Chemie, Universität Hamburg, Martin-Luther-King-Platz, 6, 20146 Hamburg, Germany \\ ${ }^{2}$ Dipartimento di Scienze Chimiche, Università degli Studi di Padova, via Marzolo 1, 35131 Padova, Italy \\ ${ }^{3}$ Ceramic Synthesis and Functionalization Laboratory, CNRS/Saint-Gobain CREE, Saint-Gobain Research Provence, 550, Ave Alphonse \\ Jauffret, 84306 Cavaillon, France \\ ${ }^{4}$ Elettra-Sincrotrone Trieste S.C.p.A., Strada Statale 14, 34149 Basovizza, Trieste, Italy \\ ${ }^{5}$ Istituto di Chimica della Materia Condensata e di Tecnologie per l’Energia, ICMATE-CNR, C.so Stati Uniti 4, Padova, 35127, Italy \\ ${ }^{6}$ Centro Levi Cases, Università degli Studi di Padova, via Marzolo 9, Padova, Italy \\ *Corresponding Author: simone.mascotto@chemie.uni-hamburg.de
}

\section{ABSTRACT}

The design of nanoporous perovskite oxides is considered an efficient strategy to develop performing, sustainable catalysts for the conversion of methane. The dependency of nanoporosity on the oxygen defect chemistry and the catalytic activity of perovskite oxides towards $\mathrm{CH}_{4}$ and $\mathrm{CO}$ oxidation was here studied. A novel colloidal synthesis route for nanoporous, high-temperature stable $\mathrm{SrTi}_{0.65} \mathrm{Fe}_{0.35} \mathrm{O}_{3-\delta}$ with specific surface area (SSA) ranging from 45 to $80 \mathrm{~m}^{2} / \mathrm{g}$ and pores from 10 to $100 \mathrm{~nm}$ was developed. High-temperature investigations by in situ synchrotron XRD and TG-MS combined with $\mathrm{H}_{2}$-TPR and Mössbauer spectroscopy showed that the porosity improved the release of surface oxygen and the oxygen diffusion, whereas the release of lattice oxygen depended more on the state of the iron species and strain effects in the materials. Regarding catalysis, light-off tests showed that low-temperature $\mathrm{CO}$ oxidation significantly benefitted from the enhancement of the SSA, whereas high-temperature $\mathrm{CH}_{4}$ oxidation is influenced more from the dioxygen release. During isothermal long-term catalysis tests however the continuous oxygen release from large SSA materials promoted both CO and $\mathrm{CH}_{4}$ conversion. Hence, if SSA maximization turned out to efficiently improve low-temperature and long-term catalysis applications, the role of both reducible metal center concentration and crystal structure cannot be completely ignored, as they also contribute to the perovskite oxygen release properties.

\section{TOC Graphics}

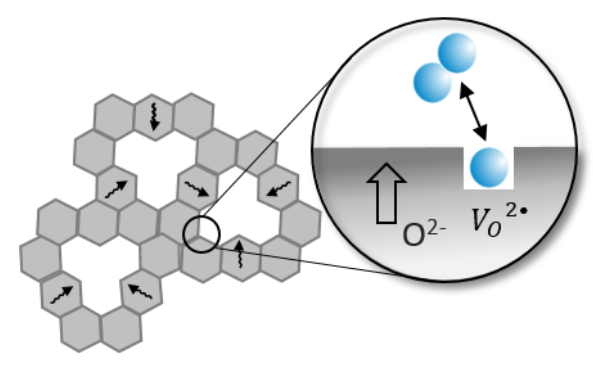




\section{INTRODUCTION}

The large employment of natural gas, composed mostly by methane, in power generation, transportation and heating generation for the last and upcoming years led to an intensive increase of its production ${ }^{1-3}$. Because hightemperature flame combustion of methane leads to the formation of harmful $\mathrm{NO}_{\mathrm{x}}$ gases ${ }^{1,3}$, the low-temperature catalytic combustion is preferred. However, such low temperature process might lead to the production of $\mathrm{CO}$ and to unburned methane, which has a greenhouse effect 25 times stronger than $\mathrm{CO}_{2}{ }^{1}$. Therefore, the development of catalysts for the full conversion of $\mathrm{CO}$ and $\mathrm{CH}_{4}$ at low temperature and with long-term stability has been actively pursued by the scientific community.

Even if noble metals display the best catalytic performances ${ }^{4}$, their criticality, high costs, poor thermal stability and scarce availability turned researchers' attention towards more sustainable systems such as metal oxides. Within this huge class of materials, perovskite oxides are commonly considered as promising systems for $\mathrm{CO}$ and $\mathrm{CH}_{4}$ oxidation, due to their ease in tolerating point defects ${ }^{5}$. Yet, despite perovskites high surface reactivity, the performance of noble metals could not be reached until now. ${ }^{5,6}$ Therefore, in the last years great attention has been dedicated to the improvement of the specific surface area of perovskite oxides. ${ }^{7-11}$ Because of the high crystallization temperature of the perovskite lattice, the design of porous architectures is not an easy task. This is particularly true when the synthesis of mesoporous perovskites, i.e. with pores between 2 and $50 \mathrm{~nm}$, is targeted. Besides the maximization of the specific surface area, mesoporous systems enable short diffusion path length for the ionic charge carriers in the mesostructured pore walls ${ }^{12}$ and display enhanced solid-gas interactions for the reactants ${ }^{13}$.

In contrast to the great effort put into the design of highly porous structures ${ }^{7,14}$, very little is known about the effective contribution that the surface enhancement has on the catalytic performance of perovskite oxides ${ }^{15}$.

With respect to thermal catalysis, it is manifest that the reactivity of perovskite oxides increases with the temperature. The surface and lattice oxygen release and the associated formation and mobility of oxygen defects (e.g. vacancies) play a key role in the Mars-van Krevelen mechanism for methane oxidation and other thermally activated catalytic processes ${ }^{5,16-19}$. Knowledge on the relationship between oxygen release, oxygen defect chemistry and the variation of the specific surface area of perovskite oxides is however still missing.

In this work, we show that the increase of the specific
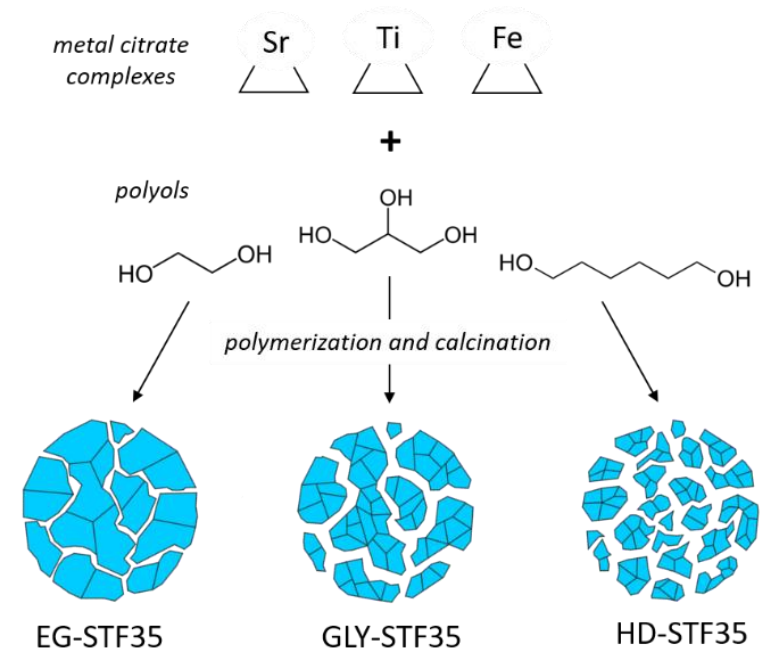

Scheme 1: Graphical representation of the synthesis of the $\mathrm{SrTi}_{0.65} \mathrm{Fe}_{0.35} \mathrm{O}_{3-\delta}$ perovskites showing the dependency of the materials porosity and crystallite size from the type of polyol (ethylene glycol, glycerol, and 1,6 hexandiol) used

surface area of perovskite oxides promotes the release of surface oxygen with the consequent formation of surface oxygen vacancies and improves the desorption of lattice oxygen over time, with favorable effects for $\mathrm{CO}$ and $\mathrm{CH}_{4}$ conversion, respectively.

To establish this, we developed a novel synthesis approach towards macro-mesoporous $\mathrm{SrTi}_{0.65} \mathrm{Fe}_{0.35} \mathrm{O}_{3-\delta}$ (STF) with specific surface areas ranging from 45 to $80 \mathrm{~m}^{2} / \mathrm{g}$ and pore sizes from 10 to $100 \mathrm{~nm}$ using a polymer complex synthesis route with polyols of different size (Scheme 1). STF was chosen because is an attractive sustainable thermal catalyst ${ }^{16,20,21}$ and is a model perovskite system with well-known defect chemistry ${ }^{22,23}$. In our previous study on mesoporous iron-doped titanates, as well as in other works, it was found that an iron concentration of about $35 \mathrm{~mol}$. \% is the most indicated to maximize the activation of lattice and surface oxygen species for methane and $\mathrm{CO}$ oxidation ${ }^{16,24}$.

The materials catalytic activity was tested for $\mathrm{CO}$ and $\mathrm{CH}_{4}$ oxidation. Besides applications in methane flameless combustion, these are also ideal reactions to probe the surface reactivity of perovskite oxides as they occur in different temperature ranges. $\mathrm{CO}$ oxidation occurs typically via a suprafacial mechanism below $300{ }^{\circ} \mathrm{C}$, whereas $\mathrm{CH}_{4}$ oxidation is a processes activated at higher temperatures and implies the involvement of lattice oxygen ${ }^{16}$.

The results obtained combining different spectroscopies, thermogravimetry and in situ $\mathrm{X}$-ray diffraction analyses showed that specific surface area and crystal structure have a significant impact on the kinetic and the amount of the released oxygen, acting as real modulators for the catalytic performance of perovskite oxide materials. 
We showed that a strong synergy between nanoporosity, oxidation state of metal centres and ionic mobility of perovskite oxides does exist and needs to be taken into account for the design of nanostructured metal oxide catalysts for $\mathrm{CO}$ and $\mathrm{CH}_{4}$ applications.

\section{EXPERIMENTAL PART}

Chemicals: Strontium nitrate (99\%, Acros Organics), titanium (IV) isopropoxide (98\%, ABCR), iron (III) nitrate nonahydrate (99\%, Merck), anhydrous citric acid (99.6\%, Acros Organics), ethylene glycol (99\%, ABCR), glycerol (99\%, Alfa Aesar), 1,6 hexanediol (97\%, Alfa Aesar), and glacial acetic acid (99\%, Acros Organics) were used as received without further purification.

Materials Synthesis: For the preparation of $\mathrm{SrTiO}_{3}$-based oxides titanium(IV) isoproxide $(3.53 \mathrm{mmol})$ was added dropwise to the liquid polyol $(0.163 \mathrm{~mol})$ at ambient temperature. After $2 \mathrm{~h}$ citric acid $(0.041 \mathrm{~mol})$ was added and the temperature raised up to $60{ }^{\circ} \mathrm{C}$ under vigorous stirring. After $1 \mathrm{~h} \mathrm{Sr}\left(\mathrm{NO}_{3}\right)_{2}(5.43 \mathrm{mmol})$ and $\mathrm{Fe}\left(\mathrm{NO}_{3}\right) \cdot 9 \mathrm{H}_{2} \mathrm{O}$ $(2.71 \mathrm{mmol})$ were introduced in the solution, which was kept under stirring for an additional hour. Subsequently, the temperature was raised to $130{ }^{\circ} \mathrm{C}$ to promote polyesterification for $2 \mathrm{~h}$ until a viscous gel was obtained. The resulting polymer gel was calcined in air with a heating ramp of $2{ }^{\circ} \mathrm{C} \mathrm{min}^{-1} .2 \mathrm{~h}$ holding time each was implemented at intermediate and final temperature steps of $400{ }^{\circ} \mathrm{C}$ and $600{ }^{\circ} \mathrm{C}$, respectively. The resulting perovskite oxide powder was then washed with glacial acetic acid (1.0 $\mathrm{mM}$ ) to eliminate carbonate impurities. The materials were labelled as follows: EG-STF35 for $\mathrm{SrTi}_{0.65} \mathrm{Fe}_{0.35} \mathrm{O}_{3-\delta}$ prepared with ethylene glycol; GLY-STF35 for $\mathrm{SrTi}_{0.65} \mathrm{Fe}_{0.35} \mathrm{O}_{3-\delta}$ prepared with glycerol; HD-STF35 for $\mathrm{SrTi}_{0.65} \mathrm{Fe}_{0.35} \mathrm{O}_{3-\delta}$ prepared with hexane diol. Thermal stability tests were performed by firing the materials at $900{ }^{\circ} \mathrm{C}$ for $2 \mathrm{~h}$ with a heating rate of $2{ }^{\circ} \mathrm{C} / \mathrm{min}$ under air and a mixture of 1 vol.\% $\mathrm{O}_{2}$ in $\mathrm{Ar}$.

Characterization methods: X-ray diffraction (XRD) patterns were collected with a X'Pert Pro diffractometer (PANanalytical Corp.) with $1.5406 \AA$ Ni-filtered $\mathrm{Cu} \mathrm{K}_{\alpha}$ radiation, operating at $45 \mathrm{kV}$ and $40 \mathrm{~mA}$, step size 0.0130 ${ }^{\circ}$, step time $7 \mathrm{~s}$ per step.

In situ X-ray diffraction (XRD) studies were carried out at the MCX beamline at Elettra Synchrotron (Trieste, Italy) ${ }^{25}$. The powdered samples were carefully packed inside quartz-glass capillaries ( $\varnothing$ int $=0.5 \mathrm{~mm}$ ) and kept under $\mathrm{Ar}$ atmosphere. Debye-Scherrer geometry with rotating capillary was used. The wavelength was calibrated using Si as external standard, while temperature calibration was achieved by measuring the thermal expansion of platinum collected under the same experimental conditions ${ }^{26}$. XRD patterns were collected in the 10-80 20-range $(\lambda=0.954$ $\AA$ ) using a translating image plate detector upon stepwise heating of $50{ }^{\circ} \mathrm{C}$ from room temperature to $600{ }^{\circ} \mathrm{C}$. The ramp time was $10 \mathrm{~min}$ with $5 \mathrm{~s}$ of temperature stabilization, the acquisition time of each XRD diffractogram was $300 \mathrm{~s}$. The diffraction data were integrated into one-dimensional powder patterns with the FIT2D software ${ }^{27}$. Rietveld refinements were performed using the GISAS sotfware ${ }^{28}$. The lattice strain was calculated using the Williamson-Hall method ${ }^{29}$.

The thermal characterization was performed with a NETZSCH STA 449F3 connected to a mass spectrometer Aeolos QMS403C. A two-step process was selected to quantify oxygen release from the materials. The first activation of the samples was performed at a heating rate of $10{ }^{\circ} \mathrm{C} \mathrm{min}{ }^{-1}$ in an $\mathrm{Ar} / \mathrm{O}_{2}$ stream (volume ratio 80/20) up to $600{ }^{\circ} \mathrm{C}$ or $900{ }^{\circ} \mathrm{C}$ for $1 \mathrm{~h}$ to remove physisorbed species (e.g. $\mathrm{H}_{2} \mathrm{O}, \mathrm{CO}_{2}$ ). After cooling down to room temperature, the volume flow was changed to pure argon and the previously described temperature program was run again. $X$-ray photoelectron spectroscopy (XPS) analyses were performed with a Perkin-Elmer $\$$ 5600ci instrument using Al- $\mathrm{K}_{\alpha}$ radiation $(1486.6 \mathrm{eV})$, operating at $350 \mathrm{~W}$. The working pressure in the analysis chamber was less than $5 \cdot 10^{-8} \mathrm{~Pa}$. The calibration was based on the binding energy (BE) of the $A u 4 f 7 / 2$ line at $83.9 \mathrm{eV}$ with respect to the Fermi level. The standard deviation for the BE values was $0.15 \mathrm{eV}$. Reported BEs were corrected for charging effects, assigning to the $\mathrm{C} 1 \mathrm{~s}$ line of adventitious carbon the $\mathrm{BE}$ value of $284.6 \mathrm{eV}$. Survey scans were obtained in the 0 $1350 \mathrm{eV}$ range (187.5 eV pass energy, $1.0 \mathrm{eV} \mathrm{step}^{-1}, 25 \mathrm{~ms}$ step $^{-1}$ ). Detailed scans (29.35 eV pass energy, $0.1 \mathrm{eV}$ step $^{-1}$, 50-150 ms step ${ }^{-1}$ ) were recorded for the O1s, C1s, Fe2p, $\mathrm{Sr} 3 \mathrm{~d}, \mathrm{Ti} 2 \mathrm{p}$ regions. The atomic surface composition of the powder, after a Shirley-type background subtraction ${ }^{30}$ was evaluated using sensitivity factors supplied by PerkinElmer using Multi-Pak 9.4.0.7 (2012) software. Peak fitting was performed using KolXPD software package.

Room Temperature Mössbauer spectroscopy was performed on a conventional constant acceleration spectrometer mounting a Rh matrix ${ }^{57}$ Co source, nominal strength $1850 \mathrm{MBq}$. The hyperfine parameters isomer shift $(\delta)$, quadrupole splitting $(\Delta)$, full linewidth at half maximum $\left(\Gamma_{+}\right)$, were expressed in $\mathrm{mms}^{-1}$ while the relative area $(A)$ in \% (Table S1). The parameters were obtained by means of standard least-squares minimization techniques. The spectra were fitted to Lorentzian line shapes with the minimum number of components. 

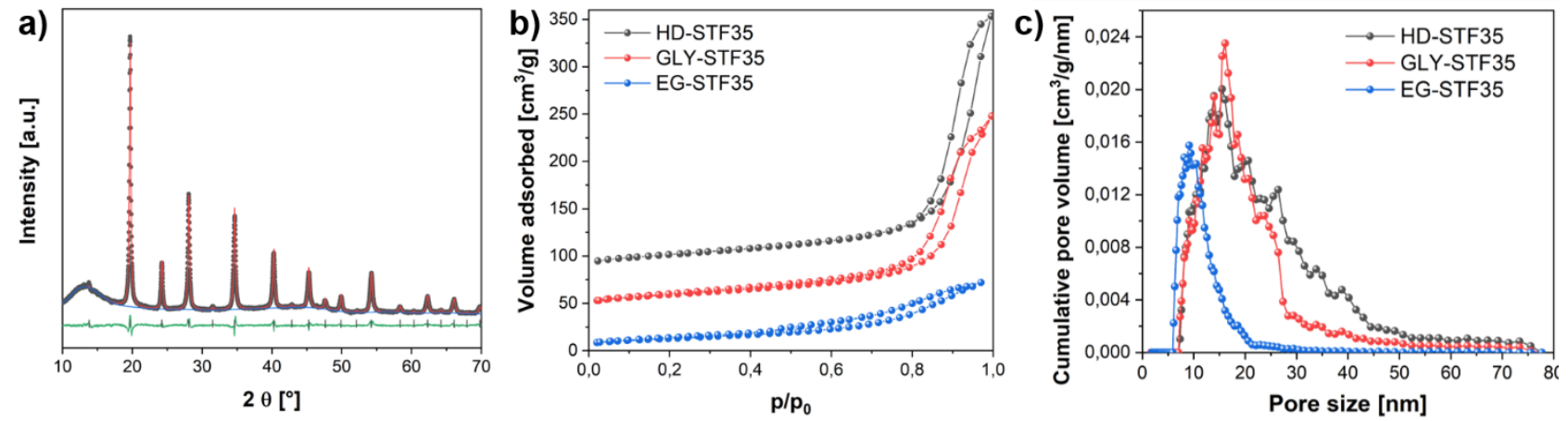

Figure 1: XRD of EG-STF35 along with its Rietveld analysis (a); Nitrogen physisorption isotherms of the investigated samples (b) along with the respective pore size distribution plots (c).

Nitrogen physisorption isotherms were obtained using a Quadrasorb SI-MP by Quantachrome at 77 K. Outgassing was performed with a Masterprep Degasser (Quantachrome Corp.) at $120{ }^{\circ} \mathrm{C}$ for 12 hours. Specific surface areas were determined with the BrunauerEmmett-Teller (BET) method ${ }^{31}$ at $\mathrm{p} / \mathrm{p} 0=0.07-0.3$. Pore size distribution was obtained with the NLDFT method ${ }^{32}$ applying the model for cylindrical pores on the adsorption branch by using the Quantachrome ASiQWin software.

Fourier Transform - InfraRed (FT-IR) analyses were performed in transmission mode by dispersing the powder in $\mathrm{KBr}$ and acquired in the region $400-4000 \mathrm{~cm}^{-1}$ (resolution $4 \mathrm{~cm}^{-1}$ ) with a Bruker Vertex $70 \mathrm{FTIR}$ spectrophotometer.

Electron microscopy measurements were obtained on a LEO1550 scanning electron microscope (SEM) operating at $2.00 \mathrm{kV}$ with a spatial resolution of $1 \mathrm{~nm}$, equipped with a Si (Li) EDX (Energy Dispersive X-ray spectroscopy) detector for composition analysis.

Transmission electron microscopy (TEM) measurements were carried out on a JEOL JEM 2200 FS operating at 200 $k V$ equipped with two CEOS CS correctors (CETCOR, CESCOR), a JEOL JED-2300 Si(Li) EDX (energy dispersive Xray spectroscopy) detector, a Gatan $4 \mathrm{~K}$ UltraScan 1000 camera and a HAADF (high angle annular dark field) detector. The sample was grinded into a fine powder, which was suspended in toluene by sonication and dropped on a carbon coated 400 mesh TEM grid. The excess of solvent was removed with a filter paper and by drying the grid under air. EDX mapping was acquired using $256 \times 256$ pixels (pixel size of $0.7 \mathrm{~nm}$ ) and a dwell time of $0.5 \mathrm{~ms} \mathrm{pixel}^{-1}$ (corrected for dead time) with 30 cycles. Additionally, EDX measurements were repeated at least on three positions for each sample and less than 1.0 at. \% disparity was observed for surveyed cations at each point. CO oxidation by molecular oxygen was carried out in a flow-through reactor. The total gas flow was kept constant to $10 \mathrm{l} / \mathrm{h}$. The composition of the gas was $6000 \mathrm{ppm}$ of CO and $10000 \mathrm{ppm}$ of $\mathrm{O}_{2}$, assuring oxidative conditions during the test. The grain size of the catalyst powder was kept between $150 \mu \mathrm{m}$ and $250 \mu \mathrm{m}$. $200 \mathrm{mg}$ of catalyst powder was put into the quartz reactor, giving a gas hourly space velocity of $50000 \mathrm{~h}^{-1}$. During the test, a heating ramp of 2 ${ }^{\circ} \mathrm{C} \mathrm{min}^{-1}$ was applied. Analysis of the effluent gases was performed using a Micro GC Gas Analyzer from Sra instruments.

Methane total oxidation was carried out using the same type of reactor and analytics, using $5000 \mathrm{ppm}$ of $\mathrm{CH}_{4}$ and $10000 \mathrm{ppm}$ of $\mathrm{O}_{2}$. The heating ramp was adjusted to $3{ }^{\circ} \mathrm{C}$ $\mathrm{min}^{-1}$, with a maximum temperature of $600^{\circ} \mathrm{C}$.

For the catalytic activity using oxygen from the materials, $100 \mathrm{mg}$ of STF was diluted in $350 \mathrm{mg}$ of SiC (grain size of all powder between $150 \mu \mathrm{m}-250 \mu \mathrm{m}$ ). The material was pretreated under $\mathrm{O}_{2}$ at $640{ }^{\circ} \mathrm{C}$ for $1 \mathrm{~h}$ (heating ramp: $10^{\circ} \mathrm{C} / \mathrm{min}$ ). $\mathrm{CH}_{4}$ oxidation was then carried out using 250 ppm of $\mathrm{CH}_{4}$ in $\mathrm{He}$ at a flow rate of $10 \mathrm{l} / \mathrm{h}$. The material was again reoxidized under $\mathrm{O}_{2}$ at $640{ }^{\circ} \mathrm{C}$ for $1 \mathrm{~h}$. $\mathrm{CO}$ oxidation was then carried out at $400{ }^{\circ} \mathrm{C}$ using $200 \mathrm{ppm}$ of $\mathrm{CO}$.

$\mathrm{CO}$ conversion and methane conversion were calculated using the general formula $F=\frac{F_{i, \text { inlet }}-F_{i, o u t l e t}}{F_{i, \text { inlet }}}$, with $F_{\mathrm{i}}$ being the molar flow rates of the inlet and outlet $\mathrm{CO}$ or $\mathrm{CH}_{4}$ flow. The rates were calculated assuming a first-order reaction rate and divided by the surface area, $k=\frac{Q_{0}}{S S A} *$ $\frac{X_{i n}}{X_{i}}$, with $\mathrm{Q}_{0}$, total flow rate, SSA the specific surface area, $X_{i n}$, the initial concentration of the gas of interest, and $X_{i}$, the conversion of the same. $\mathrm{H}_{2}$ temperature programmed reduction $\left(\mathrm{H}_{2}\right.$ TPR) experiments were carried out on an Automated Catalyst Characterization System (Autochem II 2920, micromeritics). Prior to the reduction, $100 \mathrm{mg}$ of powder was treated under oxygen at $600{ }^{\circ} \mathrm{C}$ (heating ramp: $10^{\circ} \mathrm{C} \mathrm{min}^{-1}$ ) for $1 \mathrm{~h}$. Hydrogen uptake was measured with a heating rate of $10^{\circ} \mathrm{C} \mathrm{min}^{-1}$, from $30^{\circ} \mathrm{C}$ to $1000{ }^{\circ} \mathrm{C}$ under $5 \% \mathrm{H}_{2} / \mathrm{Ar}$ and a flow rate of $30 \mathrm{ml} \mathrm{min}^{-1}$. 


\section{RESULTS AND DISCUSSION}

The microstructural properties of the mesoporous $\mathrm{SrTi}_{0.65} \mathrm{Fe}_{0.35} \mathrm{O}_{3-\delta}$ solid solutions were investigated by synchrotron XRD. The Bragg reflections were in agreement with the iron-doped $\mathrm{SrTiO}_{3}$ structure (91062-ICDS card, Figure 1a, Figure S1). Rietveld refinements in the Pm-3m space group determined an average atomic concentration of $\mathrm{Fe}$ of $38 \%$ in good agreement with the nominal composition. The average crystallite size $(\phi)$, decreased from 25 to $15 \mathrm{~nm}$ (Table 1 ) when large polyols were used in the synthesis. The reason for such behavior likely lies with the formation of highly entangled polymer complex networks, leading to localized crystal growth, as we already observed ${ }^{16,29}$. The lattice parameter was slightly smaller for the EG-STF35 material. This effect might be indicative of a higher content of $\mathrm{Fe}^{4+}$, which has smaller ionic radius than $\mathrm{Fe}^{3+}$ (Table 1$)^{16,33}$. Further, this material showed a less defective structure as indicated by the smaller oxygen vacancy $\left(\delta_{\mathrm{XRD}}\right)$ value compared to the other two compounds (Table 1).

Nitrogen physisorption analyses showed that SSA and pore volume increased proportionally with the length of the polyol used (Table 1). This finding is consistent with the decrease of the crystallite size observed by XRD. All the synthesized materials present a type IV isotherm typical of mesoporous structures (Figure $1 \mathrm{~b}$ ). The steep increase of the isotherm of HD-STF35 in proximity of $p / p_{0}=1$ might be related to the presence of macropores. The mesopore size distribution gets broader and the mean pore size larger by increasing the polyol chain length (Figure 1c), and consequently it is responsible of the higher total pore volume of the materials.

Further morphological insights were obtained by electron microscopy. SEM analyses indicated particles of several micrometers (Figure S2). While for small polyols only mesopores are detected, HD-STF35 consists of macropores of approx. $100 \mathrm{~nm}$ separated by mesoporous walls (Figure 2a,b), in good agreement with gas physisorption. Similar results are obtained by TEM (Figure 2c,d, Figure S3). The micrographs evidenced a structure with smaller pores for EG-STF35, with respect to the other materials, as predicted by the pore size distribution results (Figure 1c). High-resolution analyses show crystalline grains of approx. 10-20 nm (Figure S3), demonstrating the complementary character of TEM with $\mathrm{XRD}^{34}$. Hightemperature treatments at $900{ }^{\circ} \mathrm{C}$ were performed to assess the material stability (see Figure S4, Table S2). The systems maintained the mesoporous structure and more than half of the original SSA, demonstrating that the proposed synthesis engenders nanoporous perovskites with remarkable structural robustness.

The composition of the materials was investigated by EDXS from both TEM and SEM, and by XPS spectroscopy (Figures S5-S7, Table 1, Tables S3-S6). Besides high compositional homogeneity (Figure 2e), all the materials present surface excess of the B-site cations, likely due to the removal of $\mathrm{SrCO}_{3}$ impurities by acetic acid ${ }^{29}$ (Figure S8). The iron concentration lies between 30-40 \% atomic for all the systems, in good agreement with the XRD results. All samples presented in XPS Fe $2 p_{3 / 2}$ peaks at around $710 \mathrm{eV}$ and $713 \mathrm{eV}$. These values are compatible with $\mathrm{Fe}$ in an oxidation state of +2 and +3 . 


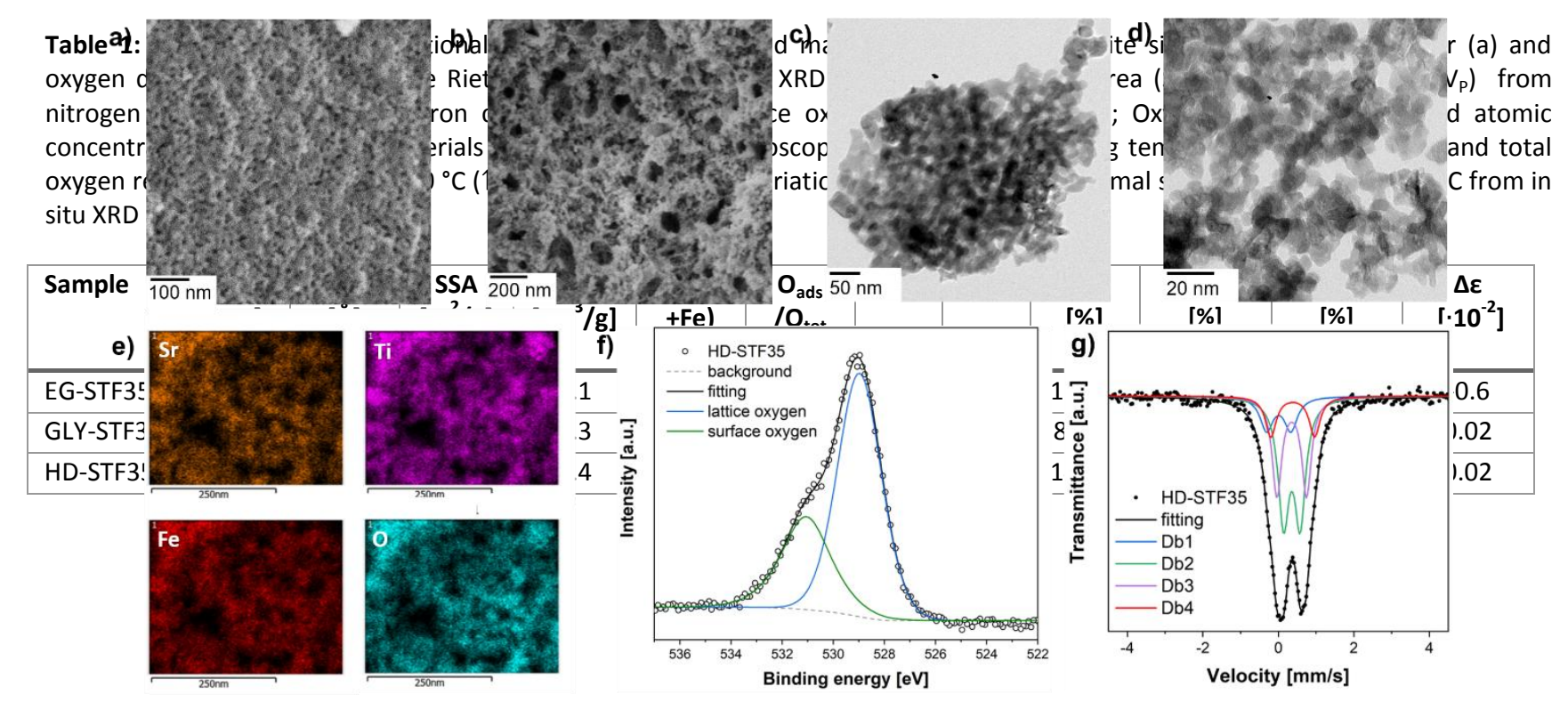

Figure 2: SEM images of the samples EG-STF35 (a) and HD-STF35 (b); TEM images of the samples EG-STF35 (c) and HD-STF35 (d); TEM-EDX elemental map of HD-STF35; (e) O1s spectrum from the XPS analysis of HD-STF35; (f) Mössbauer spectrum of HD-STF35 showing the different Fe components present in the materials $(g)$.

The occurrence of the one or the other species is determined by the satellite peak position. Binding energy shifts ( $\triangle B$.E.) of $6 \mathrm{eV}$ would be indicative of $\mathrm{Fe}^{2+}$, whereas $\triangle$ B.E. of $8 \mathrm{eV}$ is diagnostic of $\mathrm{Fe}^{3+}$. So, EG-STF35 denotes mainly $\mathrm{Fe}^{3+}$ surface species whereas for the other systems the $\mathrm{Fe}^{2+}$ component is mainly present. The partial reduction to $\mathrm{Fe}^{2+}$ in the high porous materials can be associated to the formation of surface oxygen vacancies ${ }^{35}$, which is consistent with the larger oxygen deficiency found for these materials by XRD $\left(\delta_{\mathrm{XRD}}\right)$. The surface chemistry of the oxygen species was studied by the $01 \mathrm{~s}$ spectra. This region was fitted with two or three components (Figure 2f). The signals at $529 \mathrm{eV}$ and $531 \mathrm{eV}$ belong to the lattice oxygen and to hydroxides/chemisorbed oxygen, respectively ${ }^{29}$. A contribution at $533 \mathrm{eV}$ is characteristic for physically adsorbed oxygenated species ${ }^{36,37}$ (e.g. water) and was detected only in GLY-STF35. As displayed in Table 1, adsorbed oxygen species are mainly present in GLY-STF35 and HD-STF35 materials, in good agreement with the larger oxygen defect concentration from XRD and the SSA of these systems.

Mössbauer spectroscopy was employed to characterize the oxidation state and chemical environment of the iron species in the materials (Figure $2 \mathrm{~g}$, Figure 59). All the spectra indicate an intense, broad and slightly asymmetric doublet $(\mathrm{Db})$ due to the presence of different Fe moieties. In EG-STF35, the best fitting consists in the superimposition of a doublet (Db1) due to $\mathrm{Fe}^{4+}$, together with other two components (Db2 and Db3) attributable to $\mathrm{Fe}^{3+} 38$. GLY-STF35 and HD-STF35 show, in addition to Db1,
$\mathrm{Db} 2$, and $\mathrm{Db} 3$, also a supplementary ferric doublet, Db4. Contrary to XPS no ferrous site was detected indicating that its presence was only limited to the material surface. Concerning Db1, it is present in all the spectra with a relative intensity between 7 and 18\%. Db1 has hyperfine parameters (see Table S1) typical of $\mathrm{Fe}^{4+}$ in non-cubic symmetry. The two ferric sites, Db2 and Db3, differ each other for the value of quadrupole splitting and for site population: $\mathrm{Db} 2$, with the lowest $\Delta$ value, is slightly more populated than $\mathrm{Db} 3$. On the basis of the $\Delta$ values, Db2 can assigned to six-coordinated ferric ions, while $\mathrm{Db} 3$ to fivecoordinated ones ${ }^{39}$. The formation of these sites can reasonably be the consequence of a short-range ordering of oxygen vacancies in the perovskite lattice. The extent of oxygen deficiency $\left(\delta_{M}\right.$, Table 1$)$ can be determined by the relative areas of $\mathrm{Db} 1, \mathrm{Db} 2$ and $\mathrm{Db} 3$ components, assuming equal Debye-Weller factors for $\mathrm{Fe}^{3+}$ and $\mathrm{Fe}^{4+}{ }^{40}$. The values agree very well with those obtained by XRD for EG-STF35, whereas those for GLY-STF35 and HD-STF35 are underestimated. Because Mössbauer spectroscopy considers only the oxygen deficiency engendered by substitutional ferric sites in the perovskite lattice, the slight difference found in the high porous materials corroborates the existence of additional oxygen vacancies on the materials surface. Such defects might also be related to the additional doublet in GLY-STF35 and HDSTF35 (Db4), which can be assigned to distorted six-fold ferric sites.

High-temperature characterization 

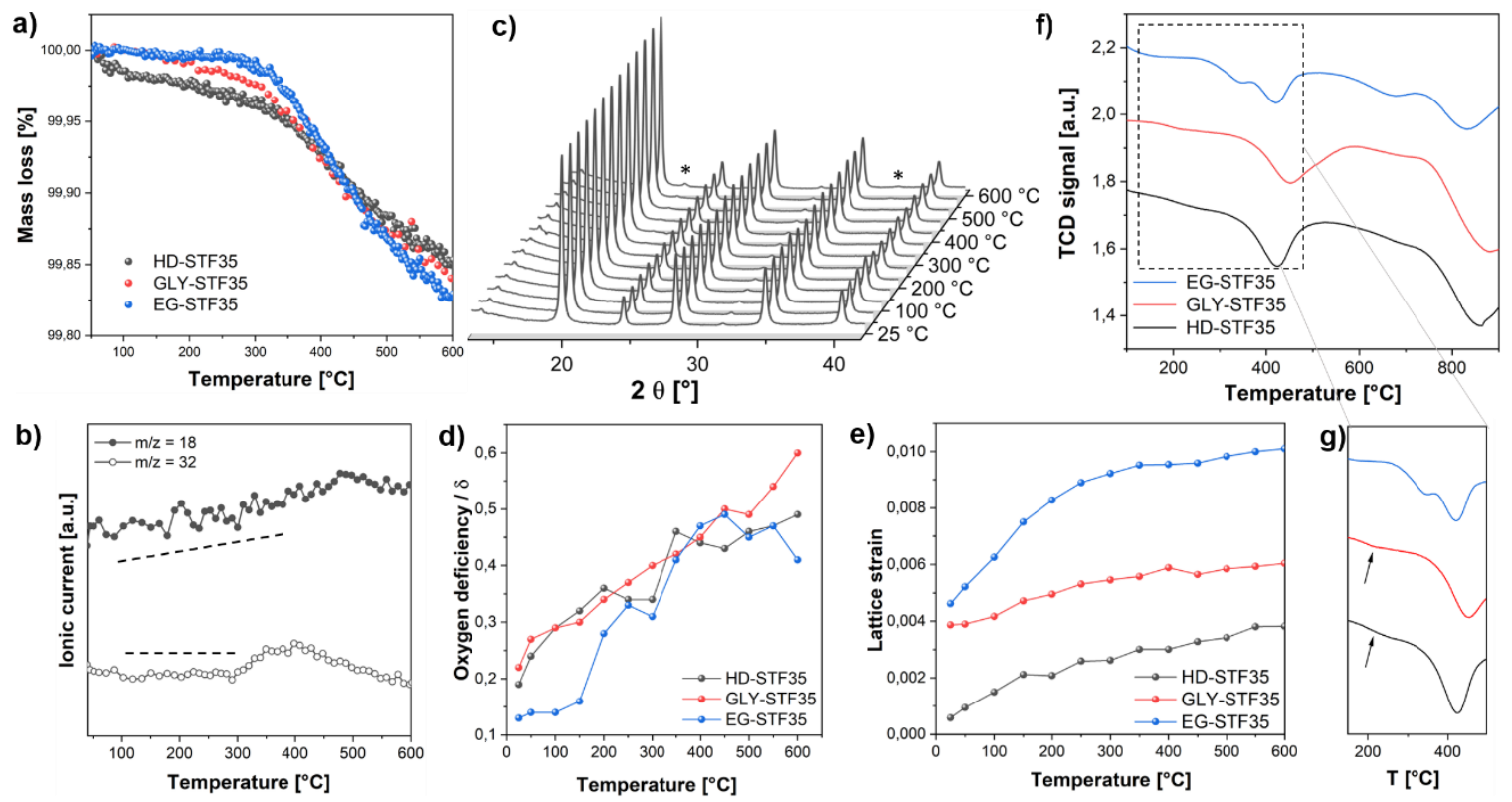

Figure 3: Mass loss of the materials from the thermogravimetric measurements under Ar atmosphere (a), mass spectrogram of HDSTF35 during the thermogravimetric measurement (b), in situ XRD of EG-STF35 under Ar atmosphere evidencing the formation of a spinel phase $\left({ }^{*}\right)$ at higher temperatures (c), oxygen deficiency (d) and lattice strain (e) of the materials obtained from the Rietveld refinements of the in situ XRD experiments, $\mathrm{H}_{2}$-TPR analysis of the materials ( $f$ ) along with the magnification of the low-temperature region $(\mathrm{g})$.

At high temperature and under low oxygen partial pressure the mutual presence in STF of oxygen vacancies and substitutional $\mathrm{Fe}^{4+}$ and $\mathrm{Fe}^{3+}$ centers promotes the release of oxygen from the oxide structure with consequent reduction of the iron species as shown by the following defect reactions:

$$
\begin{gathered}
O_{O}^{\times} \rightarrow \frac{1}{2} O_{2}+V_{O}^{2 \bullet}+2 e^{\prime} \\
2 F e(I I I)_{T i}^{\prime}+2 e^{\prime} \rightarrow 2 F e(I I)_{T i}^{2 \prime}
\end{gathered}
$$

where $O_{O}^{\times}$represents the lattice oxygen, $V_{O}^{2 \cdot}$ the oxygen vacancy, $F e(I I I)_{T i}^{\prime}$ substitutional $\mathrm{Fe}^{3+}$ and $F e(I I)_{T i}^{2 \prime}$ substitutional $\mathrm{Fe}^{2+}$ in the Kröger-Vink notation. ${ }^{41}$ Evaluation of the oxygen release capability of the STF materials was performed by thermogravimetry analyses coupled with mass spectrometry under Ar atmosphere. In Figure $3 a$ the mass losses of the STF samples up to $600^{\circ} \mathrm{C}$, i.e. the annealing temperature, after the pretreatment step in air at $600^{\circ} \mathrm{C}$, are displayed. The pretreatment step is necessary for the removal of all the physisorbed compounds like $\mathrm{H}_{2} \mathrm{O}, \mathrm{CO}_{2}$ (Figure S10a). In the thermogramms three regions can be identified. The lowtemperature region $\left(T<300^{\circ} \mathrm{C}\right)$ corresponds to the mass loss of oxygenated species (i.e. $\alpha$-oxygen) from the surface layers. From the high-temperature region $\left(300{ }^{\circ} \mathrm{C}<\mathrm{T}<\right.$ $600{ }^{\circ} \mathrm{C}$ ) also the release of intrafacial species (i.e. $\beta$ oxygen) occurs (Figure 3b). Interestingly, EG-STF35 does not present any low-temperature release. The high-porous samples show increasing desorption of oxygenated species proportional to their SSA, corroborating the observation of XPS (see $O_{\text {ads }} / O_{\text {tot }}$ in Table 1). From the high-temperature region, EG-STF35 displays a faster and larger release of dioxygen. One possible explanation is the large concentration of $\mathrm{Fe}^{4+}$ ions (Table 1). These get more readily reduced thus providing higher oxygen (Eq. 1a,b) desorption.

For the high-porous systems, the amount of oxygen released during the temperature ramp was lower than the total one, obtained after a dwell time of 1 hour at $600{ }^{\circ} \mathrm{C}$ (Table 1, Fig. S10b). This effect might probably depend on a favorable distribution of the oxygen vacancies in the small oxide grains, which decreases the activation barrier for the release, promoting oxygen diffusion through the lattice.

In order to obtain further insights into the dependency between oxygen loss, material porosity and composition, we evaluated the oxygen release properties via TG (see Figure S11) of the perovskites annealed at $900{ }^{\circ} \mathrm{C}$ (Figure S4). These experiments strengthen the evidence that the surface oxygen release is directly dependent on the surface defect structure and on the SSA of the materials, whereas the lattice oxygen release seems to enhance proportionally with the $\mathrm{Fe}^{4+}$ concentration and is SSAindependent.

To address defect structure variations during oxygen release experiments, in situ synchrotron XRD studies 

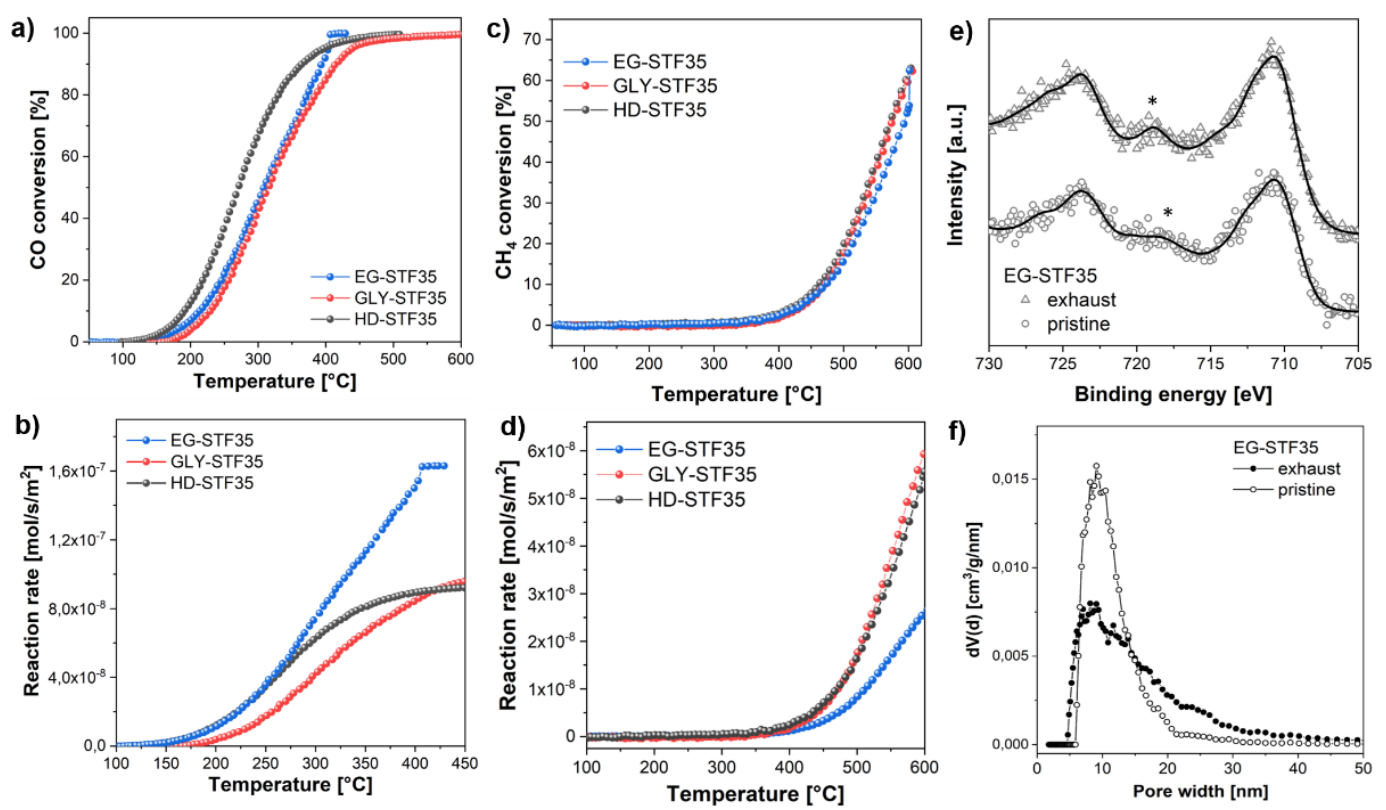

Figure 4: Light-off curves of the CO conversion (a) and respective reaction rate normalized by the SSA of the materials (b); Light-off curves of the $\mathrm{CH}_{4}$ conversion (c) and respective reaction rate normalized by the SSA of the materials (d); XPS spectra of the Fe 2p for EG-STF35 before and after methane oxidation (e); pore size distribution of EG-STF35 before and after methane oxidation (f).

under the same environmental conditions of TG experiments were performed (Figure 3c, Figure S12, Table S7). From the refinement analyses, the $\delta$ variation was determined (Figure 3d). The match with the oxygen loss registered by TG-MS is very clear. In the low-temperature region $\left(T<300^{\circ} \mathrm{C}\right)$ the samples with higher porosity show an immediate increment of the surface oxygen deficiency in full agreement with their mass loss profiles. For EGSTF35, the oxygen vacancies start to be formed only at 200 ${ }^{\circ} \mathrm{C}$, clearly indicating the poor surface oxygen concentration in this material. In the high-temperature range, EG-STF35 shows steeper increase of oxygen deficiency, in agreement with its faster oxygen loss observed by the TG. This effect is also clearly related with the lattice strain enhancement for this material (Figure 3e). Strain effects are well-known to be responsible for reducing oxygen vacancy formation energy, improve oxygen mobility and its exchange rate in perovskite oxides ${ }^{42-46}$. After 1 hour at $600{ }^{\circ} \mathrm{C}$, XRD analyses showed a stop of oxygen vacancy formation in all materials and a dramatic drop of the strain for EG-STF35 (Table 1, Table S7). The comparison of these findings with the TG analysis tells us two things: firstly, that the additional oxygen release showed by HD-STF35 and GLY-STF35 during this isothermal step is due to improved diffusion of the oxide ions through the highly defective lattice and, secondly, that oxygen release in EG-STF35 is mainly driven by lattice deformations. We believe that such lattice strain effects are related to the reduction of the numerous $\mathrm{Fe}^{4+} / \mathrm{Fe}^{3+}$ centers in EG-STF35, which is a temperature activated material property (see Figure S11) ${ }^{44}$.

The remarkable oxygen release capability of the materials leads to inevitable structural rearrangements. Iron-based spinel structures form at high temperatures (* in Figure3c) as result of the enhanced concentration of reduced $\mathrm{Fe}^{2+}$ species (Eq. 1a,b).

Deeper information on the reduction of the surface iron centers in the materials were obtained by $\mathrm{H}_{2}$-TPR analyses. From the curves in Figure $3 f, g$ three main reduction processes can be identified. A first weak feature at approx. $200{ }^{\circ} \mathrm{C}$ is visible in the high porous samples GLYSTF35 and HDSTF35, and can be associated to the reduction of iron species correlated with the low-temperature release of surface oxygen species (Figure 3f). Between 400 and 600 ${ }^{\circ} \mathrm{C}$ an intense peak is visible for all the materials, which corresponds well to the major oxygen release observed in the TG-MS analysis. This signal is likely associated to the $\mathrm{Fe}^{3+} \rightarrow \mathrm{Fe}^{2+}$ reduction. ${ }^{16,47}$ EG-STF35 displays a rather flat profile in the low temperature region $\left(\mathrm{T}<300{ }^{\circ} \mathrm{C}\right)$, in agreement with TG and in situ XRD analyses. At higher temperatures, two distinct signals are observed, the first of which can be assigned to the reduction of $\mathrm{Fe}^{4+}$ or to the presence of $\mathrm{Fe}^{3+}$ in different chemical environments. ${ }^{4}$ Finally the broad signal at temperatures above $800{ }^{\circ} \mathrm{C}$ is assigned to the $\mathrm{Fe}^{2+} \rightarrow \mathrm{Fe}^{0}$ reduction.

\section{Catalysis tests}


The mesoporous perovskites were tested for $\mathrm{CO}$ and $\mathrm{CH}_{4}$ total oxidation. In general, the materials were thermochemically stable upon cycling, and a pretreatment under oxidative conditions to remove surface impurities showed no impact on the catalytic performance (see Figure S13). In the following, light-off and long-term tests performed without pretreatment are discussed. Figure $4 a$ shows the $\mathrm{CO}$ oxidation light-off curves. Full conversion is reached by approx. $400{ }^{\circ} \mathrm{C}$ for all the samples. The performance of GLY-SF35 and EG-STF35 were comparable, whereas HD-STF35 showed better conversion, indicating that the specific surface area above a certain threshold has an impact.

In order to verify whether other factors contribute to the catalytic performance, we normalized the reaction rate by the SSA (see Figure 4b). The reaction rate of EG-STF35 increased constantly and, contrarily to HD-STF35, kept increasing above $250{ }^{\circ} \mathrm{C}$. This effect is likely related to the higher molecular oxygen release rate in EG-STF35, already considered as a key parameter for $\mathrm{CO}$ oxidation over perovskite oxides ${ }^{48,49}$. The large centration of surface oxygen vacancies in the high porous materials does not bring significant benefits. The reaction rate is equal or below the one of EG-STF35 for $\mathrm{T}<250^{\circ} \mathrm{C}$. The plateau observed at higher temperatures is indicative for surface saturation. It is likely, that during CO oxidation surface oxygen vacancies saturated, thus inhibiting their replenishment by molecular oxygen.

Concerning the $\mathrm{CH}_{4}$ oxidation, all materials were very stable upon cycling at higher temperature (Figure 4c). The impact of the SSA was not as remarkable as for the CO oxidation, and only a slight improvement for HD-STF35 was observed. Due to the higher temperature necessary for this reaction, the effect of the higher specific surface area appears to be counterbalanced by the stronger dioxygen release of EG-STF35. Also, we found that the concentration of surface oxygen vacancies plays a significant role. From the analysis of the reaction rate (Figure 4d), HD-STF35 and GLY-STF35 possess higher turnover, which is ascribed to their higher concentration of surface oxygen defects, which are well-known to promote the dehydrogenation of methane ${ }^{36,37,50}$. These results are in very good agreement with our recent findings ${ }^{16}$, indicating that the reaction rate of methane oxidation on perovskite of similar composition is determined by a cooperative action of both surface and lattice oxygen species.

Additional evaluation on the impact of the released oxygen on the catalytic application of the materials was achieved by investigating the long-term conversion of $\mathrm{CO}$ and $\mathrm{CH}_{4}$ at $400{ }^{\circ} \mathrm{C}$ and $640^{\circ} \mathrm{C}$, respectively, in absence of oxygen in the gas feed (Table 2, Figure S14). Under these reducing conditions, the oxygen in the material is triggered towards the surface and used for the $\mathrm{CO}$ and $\mathrm{CH}_{4}$ oxidation. In both cases, the amount of $\mathrm{CO}_{2}$ produced shows that the materials with high porosity perform better than EG-STF35. This indicates that the rate-limiting step of the reactions is not the oxygen diffusion in the grains, but exchange (recombination and desorption) at the surface ${ }^{4,51}$, and the development of materials with higher porosity play an important role here. This finding is in perfect agreement with the improved oxygen diffusion and release observed for the highly porous materials by

Table 2: $\mathrm{CO}_{2}$ yield during long-term tests, specific surface area $\left(\mathrm{SSA}^{\mathrm{c}}\right)$ and pore volume $\left(\mathrm{V}_{\mathrm{p}}^{\mathrm{c}}\right)$ after activation tests for $\mathrm{CO}$ and $\mathrm{CH}_{4}$ oxidation.

\begin{tabular}{|c|c|c|c|c|c|c|}
\hline \multirow[t]{2}{*}{ Sample } & \multicolumn{2}{|c|}{$\begin{array}{l}\mathrm{CO}_{2} \text { yield } \\
{[\mu \mathrm{mol} / \mathrm{g}]}\end{array}$} & \multicolumn{2}{|c|}{$\begin{array}{c}\mathrm{SSA}^{\mathrm{C}} \\
{\left[\mathrm{m}^{2} / \mathrm{g}\right]}\end{array}$} & \multicolumn{2}{|c|}{$\begin{array}{c}V_{p}^{c} \\
{\left[m^{2} / g\right]}\end{array}$} \\
\hline & $\mathrm{CO}$ & $\mathrm{CH}_{4}$ & $\mathrm{CH}_{4}{ }^{\mathrm{CC}}$ & & CO & $\mathrm{CH}_{4}$ \\
\hline EG-STF35 & 552 & 116 & 47 & 36 & 0.1 & 0.1 \\
\hline GLY-STF35 & 589 & 135 & 69 & 62 & 0.3 & 0.3 \\
\hline HD-STF35 & 589 & 135 & 82 & 67 & 0.4 & 0.3 \\
\hline
\end{tabular}

TG an in situ XRD.

In summary, the design of nanoporous perovskite oxides structures for catalytic applications has to be customized for the requirements of the targeted reaction and the applied catalysis conditions. During the temperaturedependent tests (light-off) the maximization of the SSA is certainly beneficial for low-temperature reactions as CO oxidation, which are generally surface dependent. For high-temperature processes as $\mathrm{CH}_{4}$ oxidation, the lattice oxygen release and rate is more crucial, and the materials porosity plays a secondary role. Particular emphasis needs to be put on the role of surface oxygen defects. These likely provided a significant contribution to the surface saturation in CO oxidation, whereas favored the dehydrogenation of methane at high temperature. Another scenario applies during isothermal long-term catalysis tests. Larger porosity and high defect concentration were found to improve the catalytic oxidation both of $\mathrm{CO}$ and $\mathrm{CH}_{4}$ due to larger oxygen release over time.

In addition to the catalyst performance, the chemical and structural stability of the materials after catalysis were investigated. The reduction of the iron centers correlated with the oxygen release (Eq. 1a,b) was confirmed after $\mathrm{CH}_{4}$ oxidation by the presence of $\mathrm{Fe}^{2+}$ species evidenced by the characteristic satellite peak with a splitting ( $\Delta \mathrm{B} . \mathrm{E}$.) between the main photoelectron line and the shake-up 
peak of $6 \mathrm{eV}$ of the Fe $2 \mathrm{p}$ XPS spectrum (* in Figure $4 \mathrm{e}$, Table S4-S5). The remarkable oxygen release during $\mathrm{CH}_{4}$ catalysis has relevant consequences also on the porous properties of the materials. The SSA shrunk by $20 \%$ for all investigated perovskites, but EGSTF35 showed stronger pore collapse, likely related to the larger strain effects in this system (Table 2, Figure 4f). After CO oxidation due to the lower reaction temperature, no changes in the porous features of the materials were observed (Table 2). After both $\mathrm{CO}$ and $\mathrm{CH}_{4}$ oxidation tests, all materials retained the initial microstructure, composition (with exception of the $\mathrm{Fe}^{3+} / \mathrm{Fe}^{2+}$ ratio) and elemental distribution as showed by XRD, XPS and TEM analyses (Figure S15-S18). In contrast to in situ XRD, formation of iron-based spinel structures was not observed, most probably due to the milder reducing conditions during catalysis.

\section{CONCLUSIONS}

In the present manuscript, the role of porosity on the oxygen release and the performance of nanoporous perovskite oxides towards methane and carbon monoxide oxidation was carefully studied. We developed a novel synthesis route for nanoporous, high-temperature stable $\mathrm{SrTi}_{0.65} \mathrm{Fe}_{0.35} \mathrm{O}_{3-\delta}$ with SSA ranging from 45 to $80 \mathrm{~m}^{2} / \mathrm{g}$ using polymer complexes precursors based on polyols of increasing size. High-temperature characterization of the materials, based on in situ XRD and TG-MS experiments, demonstrated that the high concentration of oxygen vacancies in highly porous structures (HD-STF35 and GLYSTF35) led to oxygen release already at $\mathrm{T}<300{ }^{\circ} \mathrm{C}$. The homogeneous distribution of these defects in the small grains of these systems is likely the reason for the prolonged oxygen desorption at $600{ }^{\circ} \mathrm{C}$. When defect concentration and porosity decreased (EG-STF35), rapid and intense dioxygen release was observed from $\mathrm{T}>300$ ${ }^{\circ} \mathrm{C}$, but stopped once reached $600{ }^{\circ} \mathrm{C}$. This mass loss was ascribed to the large $\mathrm{Fe}^{4+}$ content and the lattice strain increase in the material, leading however to substantial pore collapse.

The strong dependency between porosity, structural modifications and oxygen release in STF had significant effects on the $\mathrm{CO}$ and $\mathrm{CH}_{4}$ oxidation applications. During light-off tests, low-temperature reactions as the CO oxidation benefitted from the enhancement of the SSA, whereas for high-temperature $\mathrm{CH}_{4}$ oxidation fast lattice oxygen release is more advantageous than the material porosity. This scenario changed completely for isothermal long-term catalysis tests. Large SSA and favorable distribution of oxygen vacancies promoted the combustion of both $\mathrm{CO}$ and $\mathrm{CH}_{4}$ due to continuous oxygen release over time. This indicates that the rate-determining step of the reactions is not the oxygen diffusion in the grains, but recombination and desorption processes at the surface. In this sense, the development porous perovskite structures plays an important role.

This work demonstrates that the maximization of the SSA is particularly effective for low-temperature and long-term catalysis applications. However, the concentration of reducible metal centers, as well as lattice strain effects cannot be ignored, as they also contribute to the oxygen release properties in the materials. We could also show that only the combination of multiple characterization tools and consideration of bulk and surface properties are needed to obtain a complete picture of the hightemperature reactions and processes in perovskite oxides.

\section{SUPPORTING INFORMATION:}

XRD and electron microscopy data; Mössbauer spectroscopy fitting parameters; XPS and EDX detailed material composition; High temperature stability tests; Additional catalysis and oxygen release experiments.

\section{ACKNOWLEDGMENTS}

E.P., B.E., and S.M. were financially supported by the German Academic Exchange Service (DAAD, Project-ID 57389032). H.K. and D. A. acknowledge PHC Procope 2017 (grant no. 4048XD). S.G. gratefully thanks Centro Levi Cases (University of Padova) for the provision of funding within AmonRa project. We are indebted with Stefano Diodati and Paolo Dolcet for XPS analyses and assistance during beamtime, respectively. We thank Elettra Synchrotron, Trieste, IT for beamtime allocation, technical and financial support. Michael Fröba is kindly acknowledged for the fruitful discussions.

\section{BIBLIOGRAPHY}

(1) Chen, J.; Arandiyan, H.; Gao, X.; Li, J. Recent Advances in Catalysts for Methane Combustion. Catal. Surv. from $\begin{array}{lllll}\text { Asia } & 2015, & 19 & \text { (3), } & \text { 140-171. }\end{array}$ https://doi.org/10.1007/s10563-015-9191-5.

(2) Gélin, P.; Primet, M. Complete Oxidation of Methane at Low Temperature over Noble Metal Based Catalysts: A Review. Appl. Catal. B Environ. 2002, 39 (1), 1-37. https://doi.org/10.1016/S0926-3373(02)00076-0.

(3) Choudhary, T. V.; Banerjee, S.; Choudhary, V. R. Catalysts for Combustion of Methane and Lower Alkanes. Appl. Catal. A Gen. 2002, 234 (1-2), 1-23. https://doi.org/10.1016/S0926-860X(02)00231-4.

(4) Kayaalp, B.; Lee, S.; Nodari, L.; Seo, J.; Kim, S.; Jung, W.; Mascotto, S. Pt Nanoparticles Supported on a Mesoporous ( $\mathrm{La}, \mathrm{Sr})(\mathrm{Ti}, \mathrm{Fe}) \mathrm{O} 3-\delta$ Solid Solution for the Catalytic Oxidation of $\mathrm{CO}$ and $\mathrm{CH}$ 4. ACS Appl. Nano Mater. 2020, 3 (11), 11352-11362. 
Granger, P.; Parvulescu, V. I.; Kaliaguine, S.; Prellier, W. Perovskites and Related Mixed Oxides: Concepts and Applications; John Wiley \& Sons, 2016.

Royer, S.; Duprez, D.; Can, F.; Courtois, X.; BatiotDupeyrat, C.; Laassiri, S.; Alamdari, H. Perovskites as Substitutes of Noble Metals for Heterogeneous Catalysis: Dream or Reality. Chem. Rev. 2014, 114 (20), 10292-10368. https://doi.org/10.1021/cr500032a.

(7) Huang, X.; Zhao, G.; Wang, G.; Irvine, J. T. S. Synthesis and Applications of Nanoporous Perovskite Metal Oxides. Chem. Sci. 2018, 00, 1-15. https://doi.org/10.1039/C7SC03920D.

(8) Nair, M. M.; Kleitz, F.; Kaliaguine, S. Kinetics of Methanol Oxidation over Mesoporous Perovskite Catalysts. ChemCatChem 2012, 4, 387-394. https://doi.org/10.1002/cctc.201100356.

(9) Ji, K.; Dai, H.; Deng, J.; Zhang, L.; Wang, F.; Jiang, H.; Au, C. T. Three-Dimensionally Ordered Macroporous SrFeO3- $\delta$ with High Surface Area: Active Catalysts for the Complete Oxidation of Toluene. Appl. Catal. A Gen. 2012, 425-426, 153-160. https://doi.org/10.1016/J.APCATA.2012.03.013.

(10) Yu, J.; Ran, R.; Zhong, Y.; Zhou, W.; Ni, M.; Shao, Z. Advances in Porous Perovskites: Synthesis and Electrocatalytic Performance in Fuel Cells and Metal-Air Batteries. ENERGY Environ. Mater. 2020, 3 (2), 121-145. https://doi.org/10.1002/eem2.12064.

(11) Kayaalp, B. E.; Lee, Y. J.; Kornowski, A.; Gross, S.; D'Arienzo, M.; Mascotto, S. Cooperative Assembly Synthesis of Mesoporous $\mathrm{SrTiO}_{3}$ with Enhanced Photocatalytic Properties. RSC Adv. 2016, 6 (93), 9040190409. https://doi.org/10.1039/C6RA13800D.

(12) Gregori, G.; Shirpour, M.; Maier, J. Proton Conduction in Dense and Porous Nanocrystalline Ceria Thin Films. Adv. Funct. Mater. 2013, 23 (47), 5861-5867. https://doi.org/10.1002/adfm.201300527.

(13) Zeigermann, P.; Naumov, S.; Mascotto, S.; Kärger, J.; Smarsly, B. M.; Valiullin, R. Diffusion in Hierarchical Mesoporous Materials: Applicability and Generalization of the Fast-Exchange Diffusion Model. Langmuir 2012, 28 (7), 3621-3632. https://doi.org/10.1021/la2047432.

(14) Zheng, Y.; Zhang, R.; Zhang, L.; Gu, Q.; Qiao, Z.-A. A Resol-assisted Cationic Coordinative Co-assembly Approach to Mesoporous ABO3 Perovskite Oxides with Rich Oxygen Vacancy for Enhanced Hydrogenation of Furfural to Furfuryl Alcohol. Angew. Chemie Int. Ed. 2021, 60, 4774-4781. https://doi.org/10.1002/anie.202012416.

(15) S. Royer; Neste, A. Van; Davidson, R.; Mclntyre, S.; Kaliaguine, S. Methane Oxidation over Nanocrystalline LaCo1-XFeXO3: Resistance to SO2 Poisoning. Ind. Eng. Chem. Res. 2004, 43, 5670-5680. https://doi.org/10.1021/IE030775R.

(16) Kayaalp, B.; Lee, S.; Klauke, K.; Jongsu, S.; Nodari, L.; Kornowski, A.; Jung, W.; Mascotto, S. Template-Free Mesoporous La0.3SrO.7FexTi1-XO3 $\pm \delta$ for $\mathrm{CH} 4$ and $\mathrm{CO}$ Oxidation Catalysis. Appl. Catal. B Environ. 2019, 245, 536-545. https://doi.org/10.1016/j.apcatb.2018.12.077.

(17) Zhao, Z.; Yang, X.; Wu, Y. Comparative Study of NickelBased Perovskite-like Mixed Oxide Catalysts for Direct Decomposition of NO. Appl. Catal. B Environ. 1996, 8 (3), 281-297. https://doi.org/10.1016/0926-3373(95)000674.
Royer, S.; Duprez, D.; Kaliaguine, S. Role of Bulk and Grain Boundary Oxygen Mobility in the Catalytic Oxidation Activity of LaCo1-XFexO3. J. Catal. 2005, 234 (2), 364-375.

https://doi.org/10.1016/J.JCAT.2004.11.041.

(19) Répécaud, P.-A.; Kaper, H.; Richard, M.; Can, F.; Bion, N. Enhancement of Oxygen Activation and Mobility in CaTi $x$ Fe ${ }_{1-x} \mathrm{O}_{3-\delta}$ Oxides. ChemCatChem 2017, 9 (12), 2095-2098. https://doi.org/10.1002/cctc.201700103.

(20) Thalinger, R.; Opitz, A. K.; Kogler, S.; Heggen, M.; Stroppa, D.; Schmidmair, D.; Tappert, R.; Fleig, J.; Klötzer, B.; Penner, S. Water-Gas Shift and Methane Reactivity on Reducible Perovskite-Type Oxides. J. Phys. Chem. C 2015, 119 (21), 11739-11753. https://doi.org/10.1021/acs.jpcc.5b02947.

(21) Nenning, A.; Volgger, L.; Miller, E.; Mogni, L. V.; Barnett, S.; Fleig, J. The Electrochemical Properties of $\mathrm{Sr}(\mathrm{Ti}, \mathrm{Fe}) \mathrm{O}$ 3- $\delta$ for Anodes in Solid Oxide Fuel Cells. J. Electrochem.

Soc. 2017, 164 (4), 364-371. https://doi.org/10.1149/2.1271704jes.

(22) Jung, W.; Tuller, H. L. Investigation of Surface Sr Segregation in Model Thin Film Solid Oxide Fuel Cell Perovskite Electrodes. Energy Environ. Sci. 2012, 5 (1), 5370-5378. https://doi.org/10.1039/c1ee02762j.

(23) Metlenko, V.; Jung, W.; Bishop, S. R.; Tuller, H. L.; De Souza, R. A. Oxygen Diffusion and Surface Exchange in the Mixed Conducting Oxides SrTi1-: YFeyO3- $\delta$. Phys. Chem. Chem. Phys. 2016, 18 (42), 29495-29505. https://doi.org/10.1039/c6cp05756j.

(24) Ciambelli, P.; Cimino, S.; Lasorella, G.; Lisi, L.; De Rossi, S.; Faticanti, M.; Minelli, G.; Porta, P. CO Oxidation and Methane Combustion on LaAl1-xFexO3 Perovskite Solid Solutions. Appl. Catal. B Environ. 2002, 37 (3), 231-241. https://doi.org/10.1016/S0926-3373(02)00004-8.

(25) Rebuffi, L.; Plaisier, J. R.; Abdellatief, M.; Lausi, A.; Scardi, P. MCX: A Synchrotron Radiation Beamline for XRay Diffraction Line Profile Analysis. Zeitschrift für Anorg. und Allg. Chemie 2014, 640 (15), 3100-3106. https://doi.org/10.1002/zaac.201400163.

(26) Riello, P.; Lausi, A.; Macleod, J.; Plaisier, J. R.; Zerauschek, G.; Fornasiero, P.; IUCr. In Situ Reaction Furnace for Real-Time XRD Studies. J. Synchrotron Radiat. 2013, 20 (1), 194-196. https://doi.org/10.1107/S0909049512039246.

(27) Hammersley, A. P.; Svensson, S. O.; Hanfland, M.; Fitch, A. N.; Hausermann, D. Two-Dimensional Detector Software: From Real Detector to Idealised Image or Two-Theta Scan. High Press. Res. 1996, 14 (4-6), 235248. https://doi.org/10.1080/08957959608201408.

(28) Toby, B. H.; IUCr. EXPGUI , a Graphical User Interface for GSAS. J. Appl. Crystallogr. 2001, 34 (2), 210-213. https://doi.org/10.1107/S0021889801002242.

(29) Scholz, J.; Garbujo, A.; Kayaalp, B.; Klauke, K.; Glisenti, A.; Mascotto, S. Functional Nanostructured Perovskite Oxides from Radical Polymer Precursors. Inorg. Chem. 2019, 58, 15942-15952. https://doi.org/10.1021/acs.inorgchem.9b02460.

(30) Shirley, D. A. High-Resolution X-Ray Photoemission Spectrum of the Valence Bands of Gold. Phys. Rev. B 1972, 5 (12), 4709-4714. https://doi.org/10.1103/PhysRevB.5.4709.

(31) Brunauer, S.; Emmett, P. H.; Teller, E. Adsorption of Gases in Multimolecular Layers. J. Am. Chem. Soc. 1938, 60 (1), 309-319. https://doi.org/citeulike-article- 
(32)

d:4074706\rdoi: 10.1021/ja01269a023.

Neimark, A.; Ravikovitch, P.; Grün, M.; Schüth, F.; Unger, K. Pore Size Analysis of MCM-41 Type Adsorbents by Means of Nitrogen and Argon Adsorption. J. Colloid Interface Sci. 1998, 207 (1), 159-169. https://doi.org/10.1006/jcis.1998.5748.

(33) Ghaffari, M.; Shannon, M.; Hui, H.; Tan, O. K.; Irannejad, A. Preparation, Surface State and Band Structure Studies of SrTi (1-X)Fe (x)O (3-ס) ( $\mathrm{x}=0$ 0-1) Perovskite-Type Nano Structure by X-Ray and Ultraviolet Photoelectron Spectroscopy. Surf. Sci. 2012, 606 (5-6), 670-677. https://doi.org/10.1016/j.susc.2011.12.013.

(34) Meneghetti, F.; Wendel, E.; Mascotto, S.; Smarsly, B. M.; Tondello, E.; Bertagnolli, H.; Gross, S. Combined Use of XAFS, XRD and TEM to Unravel the Microstructural Evolution of Nanostructured ZrO2-SiO2 Binary Oxides: From Nanometres down to the Molecular Domain. CrystEngComm 2010, $12 \quad$ (5), 1639. https://doi.org/10.1039/b911004f.

(35) Ovcharenko, R.; Voloshina, E.; Sauer, J. Water Adsorption and O-Defect Formation on Fe203(0001) Surfaces. Phys. Chem. Chem. Phys. 2016, 18 (36), 2556025568. https://doi.org/10.1039/c6cp05313k.

(36) Kayaalp, B.; Klauke, K.; Biesuz, M.; lannaci, A.; Sglavo, V. M.; D’Arienzo, M.; Noei, H.; Lee, S.; Jung, W.; Mascotto, S. Surface Reconstruction Under the Exposure of Electric Fields Enhances the Reactivity of Donor-Doped SrTiO 3. J. Phys. Chem. C 2019, 123 (27), 16883-16892. https://doi.org/10.1021/acs.jpcc.9b04620.

(37) Klauke, K.; Kayaalp, B.; Biesuz, M.; Iannaci, A.; Sglavo, V. M.; D’Arienzo, M.; Lee, S.; Jongsu, S.; Jung, W.; Mascotto, S. Enhancement of the $\mathrm{SrTiO}$ Surface Reactivity by Exposure to Electric Fields. ChemNanoMat 2019, 5, 948-956. https://doi.org/10.1002/cnma.201900201.

(38) Diodati, S.; Nodari, L.; Natile, M. M.; Russo, U.; Tondello, E.; Lutterotti, L.; Gross, S. Highly Crystalline Strontium Ferrites SrFeO3- $\delta$ : An Easy and Effective Wet-Chemistry Synthesis. Dalt. Trans. 2012, 41 (18), 5517. https://doi.org/10.1039/c2dt11916a.

(39) Waerenborgh, J. C.; Figueiredo, F. M.; Frade, J. R.; Colomer, M. T.; Jurado, J. R. Fe ${ }^{4+}$ Content and Ordering of Anion Vacancies in Partially Reduced $\mathrm{AFe}_{x} \mathrm{Ti}_{1-x} \mathrm{O}_{3-}$ y $(\mathrm{A}=\mathrm{Ca}, \mathrm{Sr} ; \boldsymbol{x} \leqslant 0.6)$ Perovskites. An ${ }^{57}$ Fe Mössbauer Spectroscopy Study. J. Phys. Condens. Matter 2001, 13 (35), 8171-8187. https://doi.org/10.1088/0953$8984 / 13 / 35 / 322$.

(40) Adler, P.; Eriksson, S. Structural Properties, Mössbauer Spectra, and Magnetism of Perovskite-Type Oxides SrFe1-XTixO3-Y. Zeitschrift für Anorg. und Allg. Chemie 2000, $626 \quad$ (1), 118-124. https://doi.org/10.1002/(SICI)15213749(200001)626:1<118::AID-ZAAC118>3.0.CO;2-K.

(41) Kröger, F. A.; Vink, H. J. Relations between the Concentrations of Imperfections in Crystalline Solids. Solid State Phys. 1956, 3, 307-435. https://doi.org/10.1016/S0081-1947(08)60135-6.

(42) Koo, B.; Kwon, H.; Kim, Y.; Seo, H. G.; Han, J. W.; Jung, W. Enhanced Oxygen Exchange of Perovskite Oxide Surfaces through Strain-Driven Chemical Stabilization. Energy Environ. Sci. 2018, 11 (1), 71-77. https://doi.org/10.1039/C7EE00770A.

(43) Han, H.; Park, J.; Nam, S. Y.; Kim, K. J.; Choi, G. M.; Parkin, S. S. P.; Jang, H. M.; Irvine, J. T. S. Lattice Strain-
Enhanced Exsolution of Nanoparticles in Thin Films. Nat. $\begin{array}{lllll}\text { Commun. 2019, } 10 & \text { (1), } 1471 .\end{array}$ https://doi.org/10.1038/s41467-019-09395-4.

(44) Hwang, J.; Feng, Z.; Charles, N.; Wang, X. R.; Lee, D.; Stoerzinger, K. A.; Muy, S.; Jacobs, R.; Morgan, D.; ShaoHorn, Y. Tuning Perovskite Oxides by Strain: Electronic Structure, Properties, and Functions in (Electro)Catalysis and Ferroelectricity. Mater. Today 2019, 31, 119-120. https://doi.org/10.1016/j.mattod.2019.03.014.

(45) Mayeshiba, T.; Morgan, D. Strain Effects on Oxygen Migration in Perovskites. Phys. Chem. Chem. Phys. 2015 $17 \quad(4)$, 2715-2721.

https://doi.org/10.1039/C4CP05554C.

(46) Kubicek, M.; Cai, Z.; Ma, W.; Yildiz, B.; Hutter, H.; Fleig, J. Tensile Lattice Strain Accelerates Oxygen Surface Exchange and Diffusion in $\mathrm{La}_{1-x} \mathrm{Sr}_{x} \mathrm{CoO}_{3-\delta}$ Thin Films. ACS Nano 2013, 7 (4), 3276-3286. https://doi.org/10.1021/nn305987x.

(47) Ji, K.; Dai, H.; Deng, J.; Zhang, L.; Wang, F.; Jiang, H.; Au, C. T. Three-Dimensionally Ordered Macroporous SrFeO3- $\Delta$ with High Surface Area: Active Catalysts for the Complete Oxidation of Toluene. Appl. Catal. A Gen. 2012, 425-426, 153-160. https://doi.org/10.1016/j.apcata.2012.03.013.

(48) Tabata, K.; Kohiki, S. Catalytic Properties and Surface States of La1?X (Th, Sr) x CoO3. J. Mater. Sci. 1987, 22 (10), 3781-3783. https://doi.org/10.1007/BF01161494.

(49) Levasseur, B.; Kaliaguine, S. Effects of Iron and Cerium in $\mathrm{La}_{1-\mathrm{y}} \mathrm{Ce}_{\mathrm{y}} \mathrm{Co}_{1-\mathrm{x}} \mathrm{Fe}_{\mathrm{x}} \mathrm{O}_{3}$ Perovskites as Catalysts for VOC Oxidation. Appl. Catal. B Environ. 2009, 88 (3-4), 305314. https://doi.org/10.1016/j.apcatb.2008.11.007.

(50) Aika, K.; Lunsford, J. H. Surface Reactions of Oxygen Ions. I. Dehydrogenation of Alkanes by Oxygen(1-) Ions on Magnesium Oxide. J. Phys. Chem. 1977, 81 (14), 1393-1398. https://doi.org/10.1021/j100529a010.

(51) Salles, C.; Fouletier, J.; Marinha, D.; Steil, M.-C. Determining the Rate-Limiting Step during Oxygen SemiPermeation of CaTi0.9Fe0.103- $\delta$ Oxygen Transport Membranes. J. Memb. Sci. 2017, 527, 191-197. https://doi.org/10.1016/J.MEMSCI.2016.11.083. 
